\title{
OS ROMÂNTICOS ÍNDIOS DA AMAZÔNIA NO PROJETO DE NAÇÃO BRASILEIRA: LITERATURA E PENSAMENTO SOCIAL
}

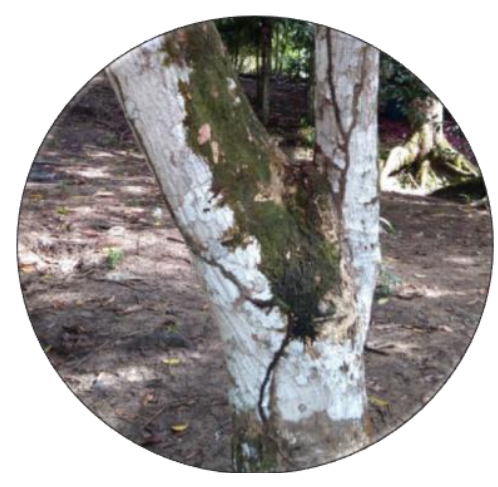

Maria Lucia Tinoco Pacheco ${ }^{1}$

\begin{abstract}
Resumo
A proposta deste texto é abrir uma reflexão em torno da representação indígena em $O$ Guarani e Iracema em contraponto aos descritos nas obras Os Selvagens e Simá. Escritas respectivamente por Francisco Gomes Ferreira e Lourenço da Silva Araújo Amazonas, as obras também indianistas e centradas no espaço amazônico, apresentam-nos outros indígenas. Mesmo publicados no mesmo período, somente os primeiros alcançaram status de clássico, fato que nos leva a pensar sobre a eleição de um paradigma indígena como referência de identidade nacional em detrimento de outros. Nesse debate é necessário tratar do contexto histórico em que os textos foram produzidos, bem como pontuar no pensamento social brasileiro o uso da literatura como instrumento intelectual de viés político e ideológico no laborioso plano de nação brasileira.
\end{abstract}

Palavras-chave: Romantismo Indianista. Pensamento Social Brasileiro. Amazônia

\begin{abstract}
The proposal of this text is to open a reflection on the indigenous representation in $\mathrm{O}$ Guarani and Iracema in counterpoint to those described in the works The Selvagens and Simá. Written respectively by Francisco Gomes Ferreira and Lourenço da Silva Araújo Amazonas, the works also indianistas and centered in the Amazonian space, present us other Indians. Even published in the same period, only the former reached classic status, a fact that leads us to think about the election of an indigenous paradigm as a reference of national identity to the detriment of others. In this debate it is necessary to deal with the historical context in which the texts were produced, as well as punctuate in Brazilian social thought the use of literature as an intellectual instrument of political and ideological bias in the laborious Brazilian nation plan.
\end{abstract}

Keywords: Indian Romanticism. Brazilian Social Thought. Amazonia

${ }^{1}$ Doutora do Programa de Pós-Graduação Sociedade e Cultura na Amazônia UFAM. Professora do Instituto Federal do Amazonas (IFAM). 


\section{Pretexto}

Três momentos me parecem corroborar com a escolha da temática proposta. Esta reflexão que visa tratar do pensamento social brasileiro à luz da literatura, no que se projetou em termos de nação e na qual o indígena tomou assento não é fortuita. $\mathrm{E}$ em que pese os distanciamentos temporais e referenciais entre esses três momentos, pareceram-me estar estritamente interligados. Daí a necessidade de explicitá-los.

O primeiro está diretamente relacionado à leitura que fiz de fragmentos da obra Simá (1857) e a crítica literária ${ }^{2}$ sobre ela, quando iniciei trabalho de docência na área de Literatura na Amazônia. Ao ler o livro em sua integralidade tempos depois, a inquietação sobre o ostracismo da obra veio à baila. Por que pouco se sabia sobre ela? Por que havia um silêncio sobre ela nos compêndios da literatura nacional?

Desde o início, percebi aproximações com Iracema (1865) de Alencar, e o inverso, de Iracema com Simá (ou Os Selvagens-1875). No entanto, guardadas as devidas singularidades da estética romântica, era visível no discurso de Amazonas, uma outra representação indígena, muito diferente daquela desenhada por Iracema ou O Guarani (1857). Mas a inquietação passou, como tantas outras que se nos apresentam e perdeu espaço para questões que julguei mais importante.

O segundo momento deu-se na pesquisa de mestrado, cujo objeto foi a obra de inglês de Sousa. Nos mesmos compêndios literários que não falavam de Simá - e nem de Os Selvagens - a obra inglesiana aparecia; mas de modo igual, o autor de o Missionário, para ser mais preciso, texto publicado antes mesmo de $O$ Cortiço, não teve o mesmo tratamento que Azevedo. Tornou-se referência nacional o texto cuja personagem era Rita Baiana. A questão era a mesma.

${ }^{2}$ Mario Ipiranga Monteiro, Jorge Tufic e Alfredo Bosi entre outros. 
O terceiro e último momento, anterior ao segundo temporalmente, relaciona-se a uma fala de um escritor manauense, durante uma palestra na semana de Letras da Universidade Nilton Lins, sobre o Modernismo Brasileiro. Perguntado sobre o Movimento Madrugada, ele foi incisivo ao dizer que o Clube da Madrugada foi eminentemente político e menos literário. Estando na plateia, retruquei com duas perguntas, também incisivas: Que literatura está desprovida de caráter político? É possível separar a produção literária do contexto social que a produz?

É possível afirmar, portanto, que esses momentos estanques se articulam e apontam para um projeto político de nação brasileira, em que muitas ideias e processos foram suplantados. A escolha de um paradigma, como bem sabemos, é sempre excludente e oculta a diversidade. A Amazônia nos parece, naquele momento inicial em que o Romantismo elege seu herói, ter sido ocultada. As obras literárias não conhecidas que nos dizem respeito são a ponta dessa exclusão.

\section{O projeto de nação e a literatura}

O contexto, em que nasce a ideia de nação e no qual o Brasil também se insere, era parte de uma conjuntura maior, bem sabemos. Alceu Amoroso Lima (1995), em Introdução à Literatura Brasileira, aponta a influência do Renascimento, da Reforma e da Revolução de XVIII como os marcos "histórico-culturais" fundadores da literatura Nacional. Considerando, pois, que a literatura não está dissociada da rede que a alimenta, esses marcos também o foram da vida política do país.

O projeto de nação se esboça a partir de uma mentalidade liberal, condicionada profundamente aos fatos históricos mencionados, e que produziria inevitavelmente uma nova sociedade. Tanto o Novo Mundo que nasce a partir dessa nova lógica de pensamento, ação e conquista quanto as colônias do Velho Mundo que vivem o clima de mudança são 
chamadas a reconstruir sua história. Nesse caso, a luta pela conquista do status de nação era o único caminho a ser tomado.

No caso brasileiro, esse projeto começa a ser delineado no século XVIII, quando explodem no território brasileiro as revoltas. São exemplos a Guerra dos Emboabas (1708), Guerra dos Mascates (1710), a Conjuração Baiana (1798), e a que mais se tornou conhecida em virtude da penalização imposta pela Coroa Portuguesa, a Inconfidência Mineira (1789). O uso dos adjetivos esboça, segundo Fausto (2002), o lugar de onde nasciam pernambucanos, baianos. Carecíamos ainda de uma unicidade: a brasilidade ainda estava em processo gestacional.

Ressalta-se ainda que no contexto da Conjuração mineira, a literatura, nas penas de seus produtores intelectuais, talvez mesmo pela proposta conteudista do estilo literário que representavam, o Arcadismo, afastava-se dessas questões. No plano pessoal, no entanto, os poetas, em sua grande maioria, eram partícipes da elite econômica, política e intelectual do país e estavam profundamente articulados com o movimento inconfidente. Tomás Antonio Gonzaga era, antes da revolta, Ouvidor de Vila Rica.

Ainda que esse movimento não tenha tido o sucesso esperado e atingido seus objetivos, não se pode afirmar que sua derrota significasse uma perda total ${ }^{3}$. Ao contrário, fortaleceu o que estava por vir, no século seguinte: a Independência do Brasil. E enquanto ela não acontecia, prosseguiu-se no projeto de uma nação. Se o Arcadismo literariamente se omitiu desse processo e ainda que o Romantismo se contrapusesse em

${ }^{3}$ [...] ... a Inconfidência Mineira. Dela foram extraídos, mesmo que a posteriori, um ideal de nação livre, bem como o mártir de uma nobre causa. Esse fato é ainda mais intrigante quando vemos que a conjuração não chegou, em ponto algum, a se concretizar, mantendo-se apenas e tão somente como boas intenções." (Botton, 2009, p.35) 
forma e conteúdo, herdou dos poetas inconfidentes o idealismo nacional e libertário.

Àquela altura, era natural que as inteligências brasileiras trabalhassem no sentido de orientar o então projeto de nação. E o que é uma nação sem povo? Como sair dos localismos das revoltas passadas e atingir a unidade necessária à nação? Nesse sentido, pensar em um ator que coadunasse o espírito de brasilidade era mister e urgente. A escolha do sujeito brasileiro certo, considerando o contexto de mudanças, poderia vir a ser o elemento desencadeador da construção identitária tão imperiosa para a nação.

A escolha e, posteriormente, a difusão do modelo ideal do brasileiro eram fundamentais nessa conjuntura. À literatura, em certo momento, coube a responsabilidade dessa tarefa. A eleição do índio como encarnação do espírito nacional não era fortuita. Ela já se havia sido tomada na longa tradição literária até ali: e os mesmos critérios parecem ter sido redimensionados. Da literatura de viagem, de Santa Rita Durão chegou a Gonçalves de Magalhães e José de Alencar. Havia uma recorrência dessa temática, nos diferentes gêneros.

É na mais nova forma da produção literária da sociedade liberal que o indígena se faz conhecer. Ao romance, de cunho folhetinesco e nova sensação ficcional, coube o papel de propagar o tipo ideal brasileiro na sociedade. Obviamente, o sucesso dependia não somente da prosa, mas também da engenharia literária e textual do autor intelectual. Nesse aspecto, indiscutivelmente, a figura de José de Alencar é aquela que se sobrepõe na historiografia literária do Brasil.

Dono de uma hábil escrita, que se desenha desde construções sintáticas precisas ao uso de recursos de estilística diversos, Alencar é autor romântico que transitou, por meio do romance folhetinesco, nas diversas etapas desse estilo que transformou seguramente a literatura. Da fase nacionalista, é que figura sua densa coleção indianista que inclui entre 
outros os clássicos O Guarani e Iracema. Mas quem era o índio alencariano? Como ele nos representava enquanto nação?

\section{Os índios brasileiros de Alencar}

Em Alencar, o projeto de nação tomou forma e conteúdo. $O$ Guarani cuja personagem central é o índio Peri, mostra-nos como grande patriarca da nação brasileira o índio, ao mesmo tempo em que assenta a brasilidade no mito da miscigenação uma vez que Cecília, seu par romântico, é branca. Em Iracema o mesmo processo se dá, porém agora a heroína é a índia dos lábios de mel e seu par é Martim, o português. Em ambos os romances, a ancestralidade brasileira está apoiada no índio, no herói romântico nacional.

A primeira dicotomia está aí: no momento em que aponta para o indígena, propõe pensar a identidade nacional com base em uma miscigenação adequada apenas entre branco e indígena. Quem somos nós os brasileiros? Índios, brancos, mestiços? A segunda dicotomia centra-se, portanto, na eleição da miscigenação, que nos parece bastante confusa, pois se a mistura é a base, qual o lugar do negro neste projeto de nação? O discurso da raça, sob esse prisma, é silenciado e deslocado para o campo mítico-religioso.

Ser brasileiro, então, era ser indígena, era ser branco, não era ser negro. No campo das ideias, a miscigenação entre os elementos eleitos ganhava força e defesas diversas. Os determinismos biológicos, advindos de pesquisa científica à época, na Europa e no Brasil, serviam de argumento para a exclusão do terceiro elemento: os negros eram inferiores ${ }^{4}$. Indígenas e brancos, a partir dessa lógica, eram competentes e, em assim sendo,

${ }^{4}$ Raimundo Nina Rodrigues (1862- 1906), brasileiro, é quem primeiro apresenta estudos sobre a inferioridade da raça negra, na Faculdade de Medicina da Bahia 
podiam copular sem prejuízo à nação, que se embranquecia cada vez mais. Ao negro ${ }^{5}$, o não olhar.

Do elemento branco, nas diversas literaturas muito já se tinha dito. Do indígena, nos textos literários de Santa Rita Durão (Paraguaçu e Moema) e Basílio da Gama (Lindóia) conhecíamos a história de sua luta e resistência diante dos brancos e da Igreja dos jesuítas. Porém essa imagem de desentendimento contrariava a consonância que pretendia o plano de nação. Assim, quando surgem Peri e Iracema em Alencar, saem de cena os índios usurpados pelos portugueses, guerreadores, defensores de sua cultura e território.

A reinvenção literária do elemento indígena punha-lhe ares universais europeus: os novos indígenas tinham altivez branca, educação branca e atitudes brancas. O exótico, a selvageria, a nudez que sempre estiveram nos textos dos viajantes e em documentos oficiais da Coroa Portuguesa e da Igreja e que não sofreram "limpeza", cederam lugar para a idealização: o índio civilizado e batizado. Havia neles agora uma compreensão da harmonia necessária nas relações com o branco que se entendia por meio de suas atitudes.

Peri, o goitacá, era estimado pela família de Cecília (Ceci), em função da bravura, pureza e inocência; as duas últimas entendidas a partir de uma compreensão cristã do mundo. A reinterpretação de o "bom

5 “O Brasil passou a ser uma nação mestiça, homogênea e não racista, o que ajudou a encobrir ou mesmo sufocar qualquer manifestação reivindicadora que fosse contra esta imagem forjada. Em outras palavras, se por um lado o mito das três raças representa um ideal nacional, por outro, é uma forma pacífica de subjugar os elementos indígenas e africanos e de promover a propagação de um sistema social que só visa aos interesses da elite." (NEVES,2011,p.19).

${ }^{6}$ A esse respeito Freitas (1995, p.11) nos afirma que "a limpeza nos relatos de viagem sempre fora operada. A escolha do que se lia e do que poderia ser lido eram objetos de especialistas, de intérpretes. O relato não circulava sem antes passar por esse processo". Se, de alguma forma, as temáticas da selvageria e da eroticidade, por exemplo, permaneceram o propósito era de fato construir argumento favorável à empresa da colonização junto aos seus. 
selvagem" nacional encontra em Peri suas principais características exaltadas. A bravura, a honestidade, a lealdade, o espírito de honradez, entre outros, é o que define esse herói puro. É nessa expressão de nacionalismo, que o mito do paraíso perdido encontra o Adão índio em estágio anterior ao pecado.

No indianismo literário, a questão étnica se perde, uma vez que é o espírito nosense do índio, tal qual o de uma criança, sem máculas de dor, de luta é o cerne. Descender de um ser desprovido de maldade, de ressentimento histórico é o ponto fundamental para a construção de uma nação nova e feliz. E embora nas histórias de Alencar as lutas existam, inclusive, amparadas no plano histórico, e envolvam os heróis, elas são mais engenhos artísticos para corroborar com essa imagem nova do índio brasileiro.

Em Iracema, a grande mãe brasileira, o projeto de nação se expande. A brasilidade miscigenada que se anuncia em o Guarani com Peri e Ceci, desta vez, se consolida por meio do nascimento de Moacir, fruto de sua união com Martim. A mãe confere ao filho legitimidade brasileira tanto no plano terreno quanto no plano espiritual. Ou seja, ele descende de uma mãe essencialmente da terra, é filho da terra, ao mesmo tempo em que reúne em si o espírito de uma nação sem mágoas, sem preconceitos, pronta para viver um novo momento histórico com o outro.

A virgem de cabelos negros é quem escolhe, por amor, seu companheiro branco. A benção desse amor, em pese o destino romântico da heroína como um preço a ser pago por infringir a regra tribal, é o nascimento do filho. Moacir nasce como uma reparação ante a morte anunciada de Iracema que preferiu o amor de Martim a seu povo. Para 
Castro (2008) essa união simboliza, de forma clara, o processo de troca ${ }^{7}$, de interesses de ambos.

Lembremo-nos que Schwartz (2000), ao estudar as origens do romance brasileiro, remonta na estrutura social brasileira, representada na literatura do romance realista de origem romântica o familismo e as relações de favor. Para ele Alencar, fruto desta sociedade liberal, reproduzia em seus textos a mesma estrutura. Não seria inadequado, dessa feita, afirmar que o mesmo problema acometera seus romances indianistas. Adivinha daí sua representação indígena e o ocultamento da questão escrava negra.

Sobre as representações indígenas de Alencar por meio das personagens Peri e Iracema, é possível afirmar que embora a idealização do herói seja uma proposta do movimento literário romântico, no romance alencariano ela cria, antes do herói, um silvícola inerte. A subserviência ganha ares de entrega amorosa, de doçura, de etiqueta, de vassalagem inquestionável ante o Senhor branco. A concordância com os termos europeus e os arroubos de consciência sobre os seus pares são redimensionadas para a causa da nação.

A traição à nação indígena, de que são protagonistas, é suplantada pelo amor e por isso alguns eventos que poderiam ser tratados de modo diferente por ele, pelos leitores e pela crítica à época foram esquecidos. O indígena criado por Alencar, entendemos, pretendia ares de civilidade branca, europeia, porque esta era uma condição sine qua non, segundo a inteligência liberal brasileira de seu tempo, para se alcançar o status de nação. Na gênese do ideal nacionalista, o argumento do mal necessário.

7 "Alencar defende o 'casamento' entre o nativo e o europeu colonizador, em uma troca de favores: uns ofereciam a natureza virgem, o solo esplêndido; outros, a cultura. Da soma desses fatores, resultaria um Brasil independente". (CHAGAS, 2008,p.48) 


\section{Os índios brasileiros da Amazônia}

Quando anteriormente discuti algumas questões postas na literatura indianista de Alencar, supus ser pertinente afirmar que, a despeito do que e de como escreveu o romancista, a proposta não era destituir sua produção ficcional. Não era desprezar a riqueza de sua linguagem, tampouco por em questionamento as construções imagéticas que produziu. Mas antes, como pontuei no início dessa interlocução, a crítica reside na adoção de um modelo exclusivo de representação.

A leitura dos romances Simá e Os Selvagens, nessa perspectiva, oferece, ainda que sem os recursos de estilística empregados no ciclo alencariano, modos de ver o autóctone por outro viés. Distante daquele sugerido pelo paradigma eleito, mas igualmente importante para a construção de uma identidade de nação, os indígenas de Amazonas e de Amorim questionam o modelo administrativo dos portugueses na Amazônia. A romantização está na escravidão a que foram submetidos e na necessidade dessa ruptura com eles.

Ressalta-se que a reflexão em torno dessa realidade de separação, da necessidade de o índio ter a autonomia na direção da sua história está em ambos os romances. Interessa-nos abrir aqui uma digressão necessária sobre o campo autoral uma vez que estando, se bem podemos assim dizer, em situações opostas, um era brasileiro, baiano e outro português, ambos apresentam as mesmas preocupações diante da problemática indígena. Questão essa camuflada em Alencar.

Simá, primeiro romance indianista amazônico, segundo Márcio Souza (1977), longe de ser apenas um romance regional, no que se refere aos estereótipos que concentram a temática dos localismos, traz indígenas que nos remetem não à história dos índios da Amazônia, mas de todo o território nacional. $\mathrm{O}$ tônus romântico não está na impossibilidade amorosa, ou na nobreza dos gestos dos indígenas embranquecidos. Está na 
impossibilidade de assumir uma identidade que se perdeu por meio do processo da conquista.

Os conflitos interculturais entre os indígenas liderados por Mabbé, que defendia a luta para reconquista territorial e o grupo de Marcos, comerciante, avó de Simá, que se contrapõe à força, revelam as tensões a mais que o europeu trouxe para as comunidades autóctones. As oposições entre essas duas personagens estão diretamente ligadas à problemática da região, ao projeto de exploração europeia ${ }^{8}$ no Brasil inegavelmente. Pela conquista do território passa também a identidade.

Marcos (que assume depois o nome de Severo), o grupo de Manau que dirige e Simá são personagens resultantes da empresa colonial no território amazônico no que se refere ao processo de alteridade. Longe de se perguntar sobre o poder dos brancos, eles buscam viver sob a égide dos portugueses na crença de que eles sejam sua melhor opção, se comparados a outros, tais quais os espanhóis. Vivem sob as determinações comerciais, religiosas e políticas do grupo que os dominou e não se questionam.

Deles, Marcos/Severo é aquele que mais representa toda a força empreendida pelos europeus no sentido de descaracterizar o outro, destituindo-o de si mesmo e tomando para si, em termos discursivos, uma identidade nova. No entanto, ao mesmo tempo em que ele legitima a fala do próprio europeu, situação que se justifica na educação que ele e Simá receberam por religiosos da ordem da Companhia de Jesus, sofre calado.

8 A trama histórica em que estão representadas as personagens é marcada pelo atravessamento de posições contraditórias dos índios que habitavam os rios Negro e Solimões. As discordâncias existentes entre os manau eram decorrentes dos dois grupos culturais que se instauram no vale amazônico e que tinham, portanto, visões distintas sobre a questão da liberdade indígena e a utilização de sua mão-de-obra para o trabalho na lavoura e serviço doméstico" (QUEIROZ, 2009, p.34) 
Sua dor, que ele não entende, está em conviver dia após dia com o vencedor.

Enquanto Mabbé compreende toda a necessidade de lutar pelo território como forma de lhes restituir o respeito pela alteridade indígena, legado que quer deixar para outras gerações, Marcos/Severo prefere a omissão, que ele julga ser sossego. E embora faça comércio com os portugueses não é isso que determina sua posição em relação a eles. Ele de fato age assim, porque é fruto, como tantos outros espalhados pelo território brasileiro, do enorme esforço que fizeram os portugueses de desacreditá-lo enquanto povo, enquanto nação.

Mas, embora o discurso de Marcos/Severo não seja seu, fato que o coloca ao lado dos portugueses, suas práticas religiosas lançam na história muitas contradições. Mais que isso apontam para o principal problema que até hoje estão presentes na vida dos indígenas que tem contato com o mundo branco: não saber o que se é. Não é indígena mais, tampouco é branco. É um híbrido amorfo, sem uma descendência cultural, sem uma perspectiva de futuro, renegados tanto por uns quanto por outros.

Simá é fruto de um estupro. Régis, o regatão português, engana Marcos e estupra sua filha Delfina, que mais tarde, depois de parir Simá, morre pela incapacidade de conviver com a vergonha e com a violência a que foi submetida. Se adoção de dois nomes pelo avô de Simá se justifica pela aventura romanesca, a tragédia de que são vítimas Marcos/Severo, Delfina e Simá está além do livro. Antes a matéria de que é feito o romance está na experiência vivida pelos indígenas do Brasil.

Quantas Simás, quantas Delfinas ficaram esquecidas e enterradas no território nacional e foram silenciadas definitivamente nas histórias de Alencar? Quantos índios como Marcos, se traduziram de forma ambígua pelo apagamento de sua memória cultural? O projeto de nação proposto pelo baiano Amazonas está longe de concordar com aquele proposto pelos intelectuais da outra parte do país. De modo igual, Amorim também se 
posiciona contrário a esse projeto de nação que elege a miscigenação entre brancos e índios como um espírito a ser cultivado no Brasil.

O romance Os Selvagens assinala desde o título a ambiguidade das ações e das personagens emblemáticas da sociedade indígena amazônica: a igreja católica e os índios. O duplo sentido reside sobre o questionamento do lugar de onde nascem as ideias, os conceitos, o olhar que determina o que o outro é. $\mathrm{Na}$ visão de Amorim tanto o índio quanto o europeu catequizador eram selvagens. Enquanto a barbárie d do autóctone estava na luta, na morte, no canibalismo, no outro prisma estava a morte religiosa e cultural promovida pela Igreja.

Ao narrar o encontro dos Mundurucu com padre Félix e, posteriormente, contar todo o processo de evangelização que se deu a partir desse encontro, Amorim deixa entrever que a única possibilidade de os índios viverem harmonicamente com os brancos está na adoção de um outro comportamento. Conduta esta, segundo Guedelha (2009), pautada no etnocentrismo europeu, na moral e ética dos brancos. Dito de outra forma, a harmonia viria na aceitação da Igreja Católica.

À medida que são catequizados, mudam de nome e com o nome vão também modificando seu modo de ver, de agir, de se vestir. Já não cultuam seus deuses, vestem-se "sua vergonha", aprendem o evangelho, não lutam mais. Mais uma vez, tanto os índios de Amorim, quanto os de Amazonas mostram o que significava consequentemente a ruptura com seus modelos culturais. A renúncia de suas raízes era o enfraquecimento de que precisava a empresa europeia de colonização para tomar posse em definitivo do Brasil.

Nem Mabbé, nem mesmo o ancião mundurucu, que compreendem o contexto em que estão, têm força suficiente para impedir o que estava se desenhando. O genocídio anunciado que se deu em toda a extensão da terra brasilis começara muito antes. Ambos os romancistas que escrevem sobre a Amazônia, em que pese as discussões de uma literatura 
genuína e distante do campo de produção como bem aponta Pressler em seu artigo "Romantismo na Amazônia?”, aproximam-se muito mais de uma representação indígena que aquela proposta por Alencar.

O Romantismo destas obras está na incapacidade de entender o que se é, na perda da identidade face ao desrespeito da alteridade. Está no apagamento da memória de toda uma vida, na dissolução dos laços míticos e tribais. Está na impossibilidade de não ser o que se foi ou de não mais se lembrar do que foi, do que era. Está na dor de conviver dia após dia com o vencedor. Vencidos pelo europeu em seu próprio território silenciam quanto à sua origem. Assim é Marcos/Severo, Delfina, Flor de Cajueiro, Simá, o cacique Pangip-hu...

O projeto de uma nova nação brasileira, na proposta desses autores, não incluía mais os europeus. Faziam parte da história brasileira e isso não se podia mais apagar. O estupro que Delfina sofrera foi o mesmo que os selvagens mundurucu de Amorim sofreram. Simá, a personagem que dá nome ao livro de Amazonas, é a representação da nação indígena vencida, da mulher indígena, das mães indígenas depois da avassaladora passagem europeia em seus domínios.

A morte romântica da personagem, antes de sugerir o escapismo, põe em suspensão o futuro de paz que vive Martim e Moacir em Iracema. A Amazônia brasileira tinha uma outra imagem de herói nacional, tinha uma outra proposta ${ }^{9}$. Os índios amazônidas eram outros, sempre foram, desde a Muburaida, e não aqueles do ciclo indianista canonizado no Romantismo Brasileiro.

\footnotetext{
9 "A proposta do autor [...] está muito mais próxima dos anseios dos brasileiros da época, preocupados em criar uma tradição, que se defrontassem com a cultura importada via Império, quando aponta o processo de descaracterização do indígena no contato com o português colonizador" (GONDIN, Neide in apresentação de Simá, 2003.)
} 


\section{Fechamentos}

Algumas pesquisas recentes sobre o indianismo e a contraposição entre os romances de Alencar, de Amorim e Amazonas têm procurado explicar o sucesso do primeiro em detrimento dos outros dois ${ }^{10}$. Há afirmações de que a forma literária, na qual aparecem costurados coerentemente enredo, personagens e pesquisa histórica é responsável pela diferença na recepção. Ou ainda que fora a habilidade de escrita, o emprego de certa linguagem que fez com que $O$ Guarani ganhasse as graças dos leitores.

Sobre isso temos a dizer que o veículo pelo qual foi apresentado o romance, o folhetim, recebeu por parte dos leitores grande aceitação, o que não se repetiu necessariamente com o livro publicado. Sendo isso uma verdade, se de fato o sucesso se devesse a aspectos relacionados à história narrada ou a linguagem usada, talvez o efeito fosse o mesmo. Não se pode justificar, portanto, que a linguagem tenha sido o critério de sustentação da obra.

Desprezar uma análise conjuntural da obra que envolve desde a questão autoral, as influências políticas e ideológicas do lugar onde nascem, o contexto de produção e até os meios econômicos responsáveis por sua circulação é se negar a ver com justeza as possibilidades de outras obras que não entraram em circuito nacional, mas não menos importante. Se todas as categorias descritas anteriormente não são analisadas não se pode falar nem de sucesso, tampouco de insucesso.

Um único juízo crítico, tomado à revelia ou eleito à luz de dado conhecimento intelectual não parece ser suficiente para se chegar a esta ou àquela conclusão. Portanto, afirmar que uma obra alcançou status de

10 Ler o texto O Guarani e Simá: propostas para o romance brasileiro à escolha do leitor, de Marlí Tereza Furtado 
clássico em detrimento de outras obras, em virtude de um critério eleito e não se questionar sobre tal fenômeno implica silenciar sobre as forças políticas, intelectuais, filosóficas e ideológicas que pensam o país, que pensam a produção científica, literária.

As pesquisas que hoje fazemos no campo da identidade, da alteridade sob viés literário no sentido de apreender o pensamento social brasileiro em dado momento histórico devem se permitir produzir senão respostas, possibilidades outras para além daquelas que já existem e que já se encontram tão encorpadas nos discursos que lemos. Não se trata de simples inovação, mas, de fato, de pesquisa e de problemas que estão postos, que nos exigem posicionamentos políticos, epistemológicos, ideológicos.

Neste sentindo, o mérito literário da obra indianista alencariana é inegável. Que se tornou um clássico, disso não se tem dúvida. Entretanto sabemos também que não se deve somente à linguagem, à forma. Além da urbanização e da vida cultural que existe com e a partir do espírito citadino, a força dos grupos políticos - intelectuais permitiram a ela ser o que se tornou. Esse me parece ser um argumento plausível que justifica o ostracismo das obras norte em dado momento.

De outro ponto, o fato de ser clássico não legitima uma realidade complexa. No caso de Alencar, ele expõe uma ideia, argumenta em prol dela, mas não a torna possível nem no plano literário, nem fora dele como se pretendia. A intelectualidade brasileira ${ }^{11}$ ao adotar o índio alencariano como modelo, como se encerrasse ou coadunasse nele todo o mundo indígena, esbarra na complexidade dessa cultura e por isso não avançou.

11 Machado de Assis, por exemplo, mesmo consciente do índio caricatural alencariano e da omissão do elemento negro no projeto de nação miscigenada proposta por Alencar, desloca seu discurso para o fazer literário que torna tudo possível. Obviamente se Machado não comungava, naquele momento, das mesmas opiniões relevou-as em nome daquele mesmo projeto. 
A imposição de um modelo único de representação do indígena brasileiro por meio da literária desfigura o projeto de nação pretendida, sobretudo porque de um lado uma nação não se faz com heróis artificiais nem sem força política, por outro, porque tornou excludente o local e o regional, igualmente necessários para o projeto de nação. Havia muitos índios e muitas outras formas de representá-los que não àquela. Simá e Os Selvagens lançam, sem dúvida, uma fagulha contra a homogeneização pretendida.

A concordância com essa forma que se pretendeu absoluta num contexto tão diverso como o é o indígena e que mantém em nosso século essa mesma heterogenia é, no mínimo, arbitrária. Apropriando-me das palavras de Schwarz (2000), diria que o índio de Alencar era "uma ideia fora do lugar", fora da realidade brasileira. Tanto na literatura quanto na vida real as personagens são múltiplas e se revertem de fragmentos ${ }^{12}$ da vida social, o que lhes confere identidade.

Depois de atingir seu ápice, o indianismo fecha seu ciclo, como era de se esperar. Mas, mais tarde, depois do processo de subjetivação do Romantismo da segunda fase, conhecida como mal do século, Castro Alves entra em cena. O projeto se realinha. O elemento esquecido, sublimado até então toma assento no cenário de nação. O índio cede lugar ao negro por razões que o próprio projeto liberal impõe.

No Realismo, estilo seguinte, a explosão machadiana e as questões como preconceito entram na ordem da nação. A literatura, portanto, não é apolítica. A própria separação em estilos, em fases, orienta-se para além de uma estética diferente, para contextos políticos e ideológicos diversos e

12 Ronaldo Oliveira de Castro (2009) afirma que parte da literatura contemporânea, na qual se inclui a brasileira, traz histórias diferentes sobre nós mesmos e que elas não supõe uma integração, nem busca redimir diferenças, desigualdades ou injustiças. As personagens são complexas, multifacetadas face aos contextos sociais em que suas histórias se desenvolvem. 
divergentes, de onde ela retira ou não a matéria de que são feitas suas histórias, seus personagens, seu enredo.

\section{Referências}

ALENCAR, José de. O Guarani. Coleção Clássicos Saraiva. São Paulo: Saraiva, 2006.

Iracema: lenda do ceará. Coleção Clássicos Saraiva. São

Paulo: Saraiva, 2006.

AMAZONAS, Lourenço da Silva Araújo. Simá - romance bistórico do Alto Amaronas. 2. ${ }^{a}$ Ed. revista. Manaus: Editora Valer, 2003.

AMORIM, Francisco Gomes de. Os Selvagens. $2^{\mathrm{a}}$ ed. revista. Coleção Resgate II. Manaus: Valer, Governo do Estado do Amazonas, 2004.

LIMA, Alceu Amoroso. Introdução à Literatura Brasileira. $5^{\mathrm{a}}$ ed. Rio de Janeiro: Agir, 1995.

CASTRO, Ronaldo Oliveira de. Pensamento Social Brasileiro e Literatura Contemporânea. In Artcultura, Uberlândia, vol.11, jul-dez, 2009.

CHAGAS, Gesilda Maria Benevenuto das. O Guarani: A Mitologia da Nacionalidade Brasileira. Dissertação apresentada ao Curso de Mestrado em Letras, do Centro de Ensino Superior de Juiz de Fora. Minas Gerais, 2008. Disponível em http://web2.cesjf.br/node/3314.

BOTTON, Flavio F. A Inconfidência Mineira: Literatura e História em dois tempos in Anuário de Literatura, vol. 14, n. 1, 2009.

FAUSTO, Boris. História Concisa do Brasil. São Paulo: Edusp/Imprensa Oficial,

2002.

FREITAS, Marilene Corrêa da Silva. Maluco e os descobridores: um ensaio de literatura e sociedade, no romance de Ponce de León. TCC de Poéticas da Ocidentalização dos Programas de Pós-Graduação do IEL/IFCHUNICAMP. São Paulo, 1995. 
FURTADO, Marlí Tereza. O Guarani e Simá: Propostas para o Romance Brasileiro à Escolha do Leitor. In XIII Encontro da ABRALIC Internacionalização do Regional. UEPB/UFCG - Campina Grande, PB. 10 a 12 de outubro de 2012 .

GUEDELHA, Carlos Antônio M. A Metáfora da Identidade Perdida em Os Selvagens. Revista Interdisciplinar. Ano VI-V.13, jan-jun de 2011. Disponível em

http://200.17.141.110/periodicos/interdisciplinar/revistas/ARQ INTER 13/INTER13 5.pdf.

GONDIM, Neide. Simá, Beiradão e Galvez, Imperador do Acre. Manaus: EDUFAM 1996.

NEVES, Kelly Cristina da Silva. O Romance e o Indígena: da Idealização à Ação Afirmativa. Dissertação apresentada ao Curso de Mestrado em Letras e Ciências Humanas da Universidade do Grande Rio - UNIGRANRIO. Rio de Janeiro, 2011.

PRESSLER, Gunter Karl. Romantismo na Amazônia? Disponível em http://www.pgletras.uerj.br/gthistoria/pressler.pdf s.d

QUEIROZ, Amilton J. Freire de. Narrativas em Trânsito: Literatura, Fronteiras e Lingua (Gens) do Alto Amazonas no Romance Simá. Dissertação apresentada ao Curso de Mestrado em Letras: Linguagem e identidade, da Universidade do Universidade Federal do Acre-Ufac. Rio Branco, 2009.

SOUZA, Márcio. A Expressão Amazonense: do Colonialismo ao Neocolonialismo. Alfa-Omega, São Paulo, 1977.

SCHWARZ, Roberto. A importação do romance em Alencar e suas contradições. In: - Ao vencedor as batatas. $5^{\mathrm{a}} \mathrm{Ed}$. São Paulo: Duas cidades, 2000. 